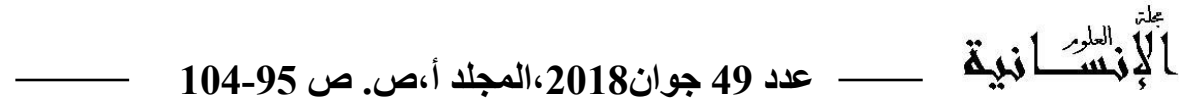

\section{إجراءات وسلطة القاضي الإداري في تقرير الغرامة التهديدية}

\section{د / نقـاش حمزة \\ كلية الحقوق \\ جامعة الإخوة منتوري \\ قسنطينة}

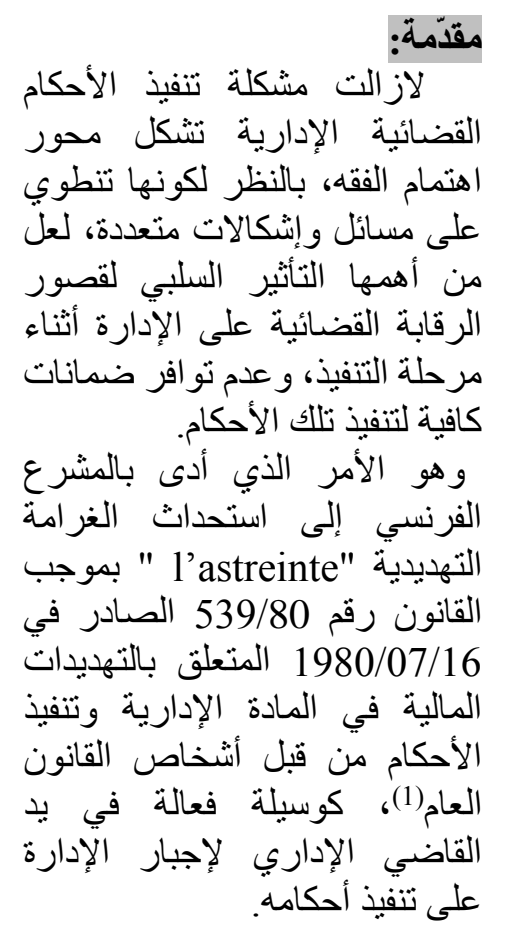

الأصل أن الإدارة ملزمة بتنفيذ الأحكام القضائية الإدارية بما لها من حجية،

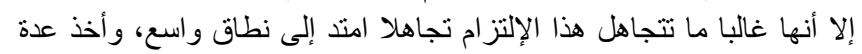

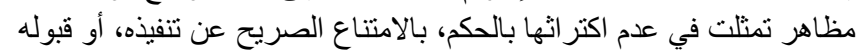

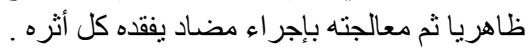

وقد تعددت الأسباب التي نوارت بارت خلفها الإدارة لتمتنع عن تنفيذ الأحكام التي

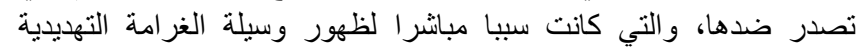

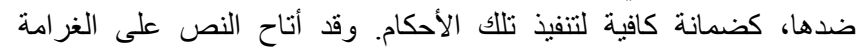

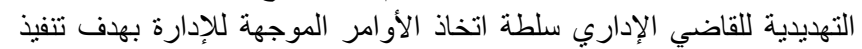

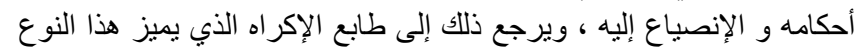

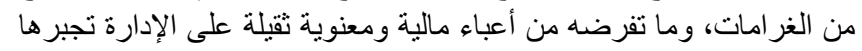

على الإذعان في النهاية لحكم القضاء.

\section{Abstract:}

In principle, the administration is to comply and execute judicial judgments that are delivered by the administrative jurisdictions as they enjoy the force of res judicata. However, it neglects this obligation in most cases, and this is manifested in several ways, such as ignoring totally the judgment, express abstention from execution, or outward acceptance of the decision and then deals with it in a way that deprive it of its effects.There are numerous reasons behind such a phenomenon, which have, in the end, led to the establishment of the threatening financial fine regime as an efficient mean to assure compliance and execution of judgment taken against it. It provide the judge with the authority to deliver orders to it for the purpose of assuring their execution and full compliance with them, and this is due to the coercive nature that characterizes this kind of fines from one side, and the heavy financial and moral burdens imposed by them upon it from the other side, which force it, in the end, to fully respect and execute judgments.
\end{abstract}




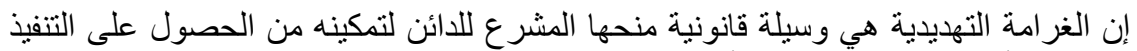

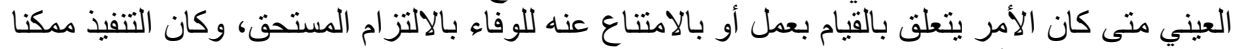

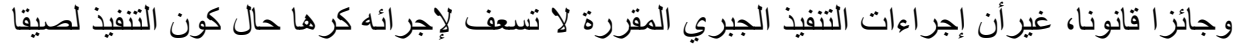

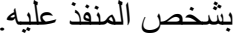

فالغرامة التهديدية هي عبارة عن المبلغ الذب يحكم به عن كل يوم تأخير، ويصدر ها القاضي

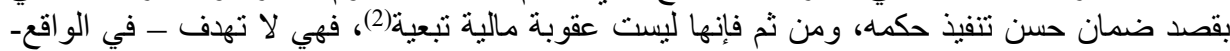

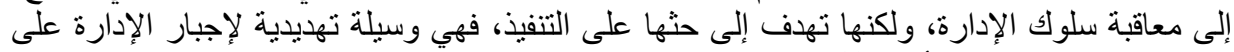

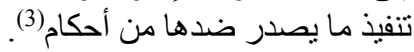

إن القاضي الإداري الفرنسي بمقتضى قاندانون العدالة الإدارية المعدل بموجب الأمر رقم

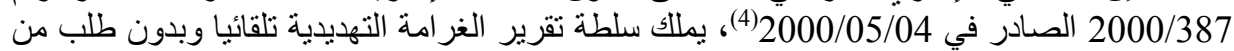

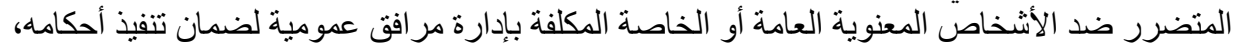

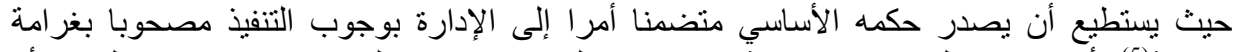
تهديدية(5)، أو يفرض أن على الإدارة غرامة بعد صدور الحكم إذا ما تبين له امتتاع الإدارة عن التتفيذ، أو الو

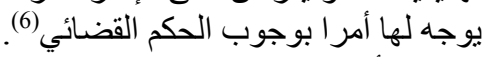

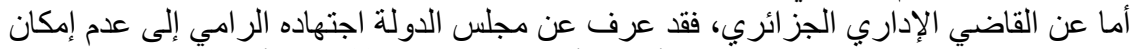

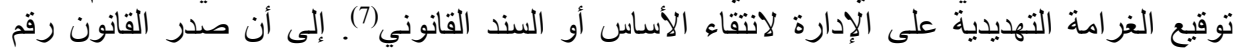

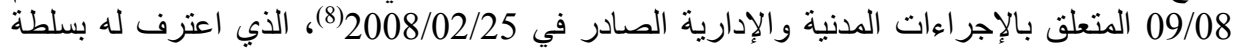
توقيع الغر امة التهديدية على الإدارة.

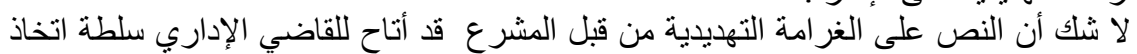

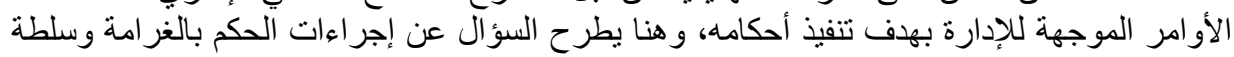

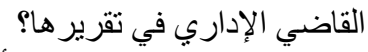

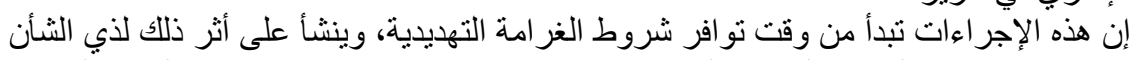
حق في اتخاذ إجراءات الحكم بالغرامة لهجابهة عنت الإدارة وممانعتها في تنفيذ الحكم ألصادر لثران لمصلفته

ويمر تنفيذ حكم الغرامة التهديدية بمرحلتين متعاقتنين، الأولى: مرحلة الحكم بالغر امة، و الثانية: مرحلة تصفية الغرامة.

\section{أولا: الحكم في طلب الغرامة التهايدية}

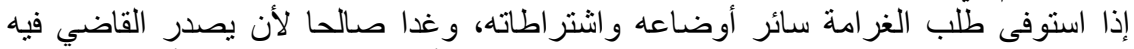

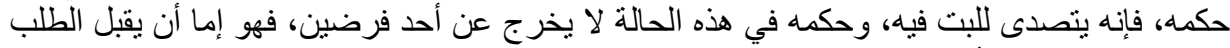

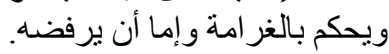

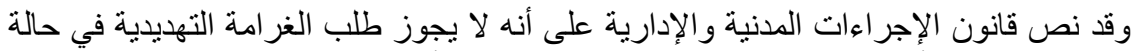

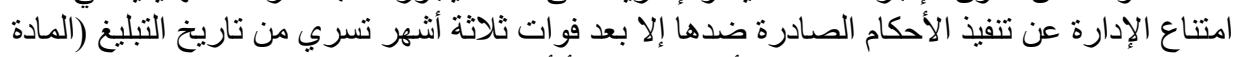

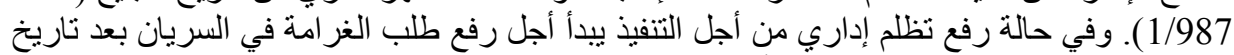

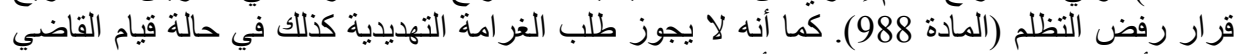

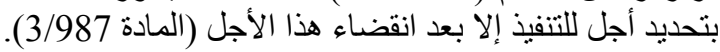

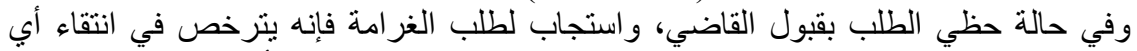

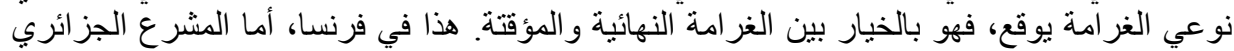
فلم يميز بين نوعي الغر امة.

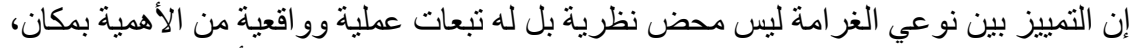
حيث يتوقف على نوع الغر امة المقضي به مدى السلطة المخولة للقاضي في إلغائها أو تعديل قيمنها حال

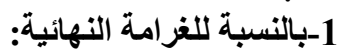


لا خلاف على حرية القاضي الإداري في توقيع الغرامة التهديدية، بمعنى أنه يتمتع بسلطة وإنة

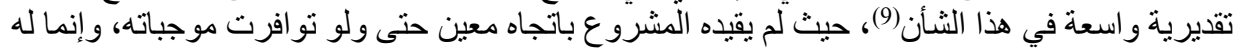

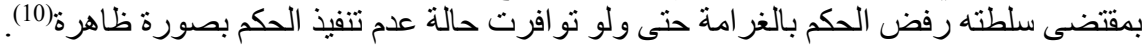

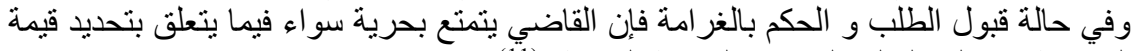

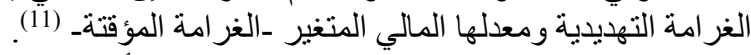

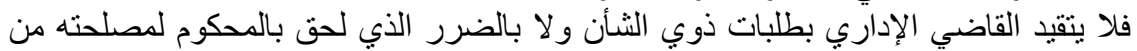

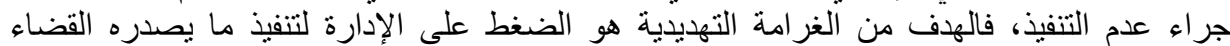

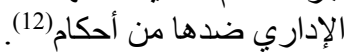

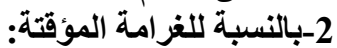

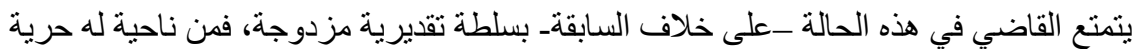

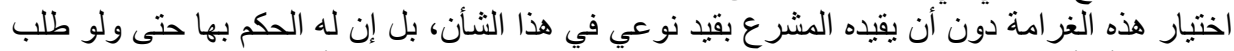

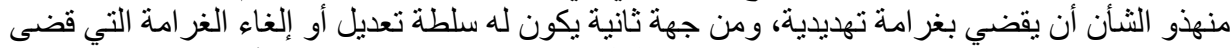

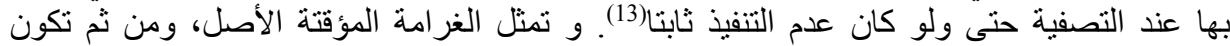

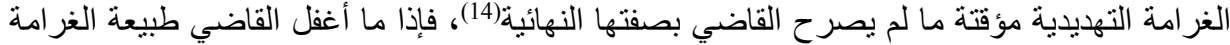

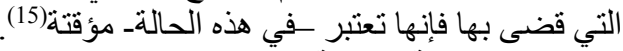
3- 3بيعة الغرامة:

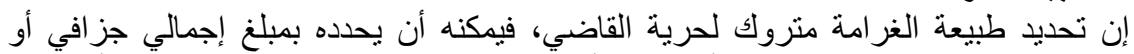

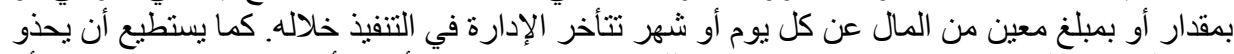

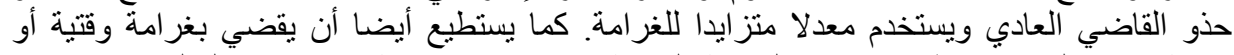

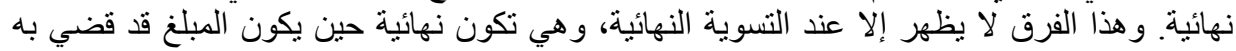

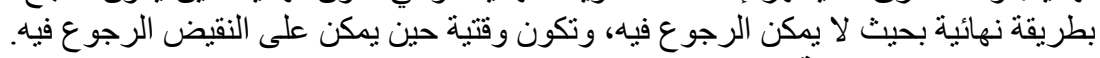

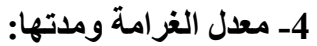

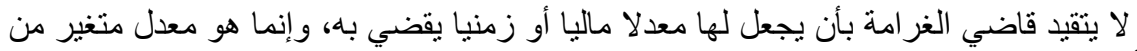

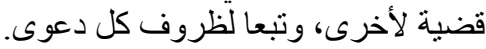
ويعتد القاضي في تقديره لها باعتبار ات ثلاث:

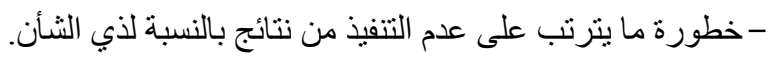
- مدى يسر الثخص المعنوي العام الممتنع عن التنفيذ أو المتأخر فيه.

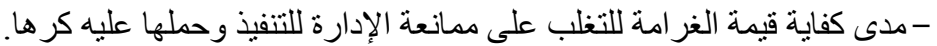

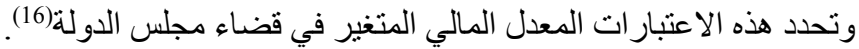

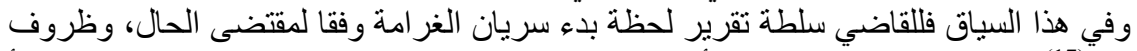

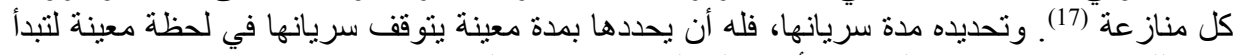

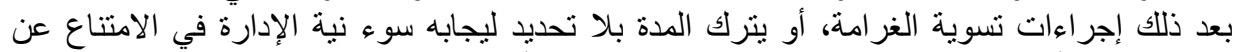

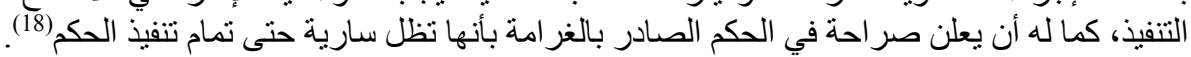

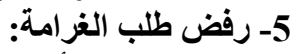

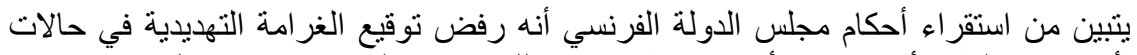

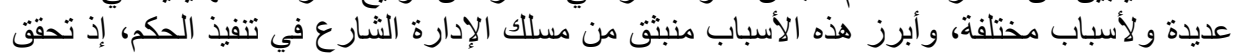

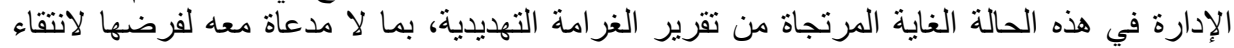

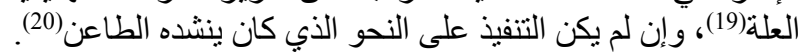

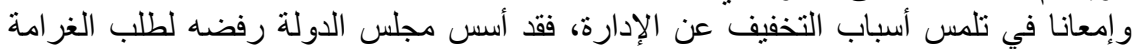

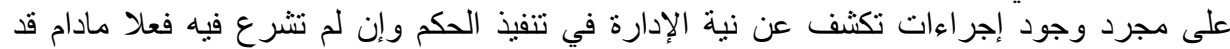

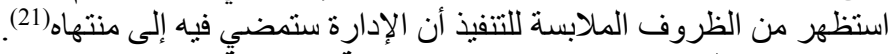
6- الطعن على الحكم الصادر بالغرامة التهديدية: 
يفترق جوار الطعن على الحكم الصادر بالغر امة التهديدية تبعا لنوع الغر امة المحكوم بها أي وفقا لما إذا كانت مؤقتة أو نهائية.

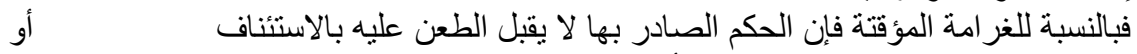

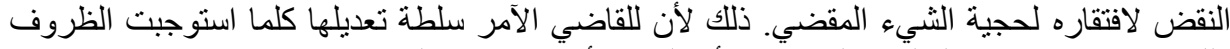

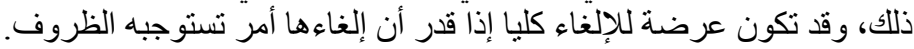

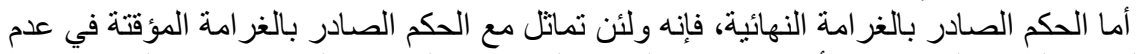

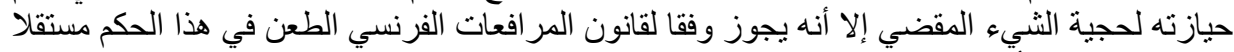

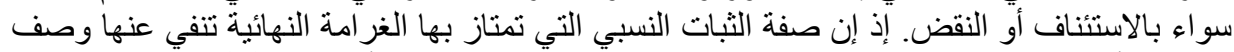

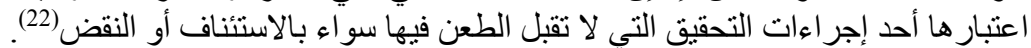

ثنانيا : تصفية الغرامة التهذيدية التئية

أقر المشرع الجزائري للقاضي الإداري في حالة عدم التنفيذ الكلي أو الجزئي،ئو في حالة

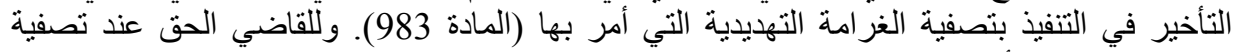

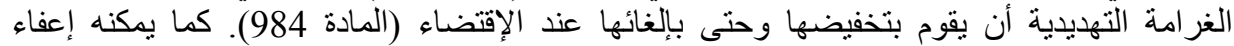

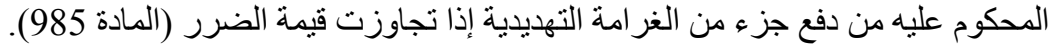

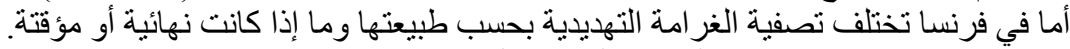
1- في خصوص تصفية الغرامة النهائية:

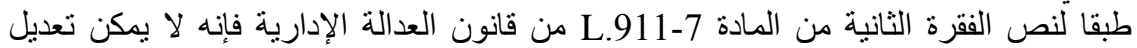

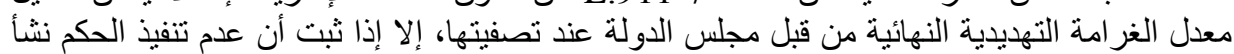

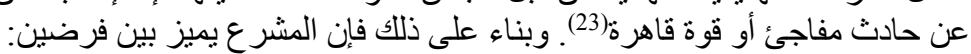

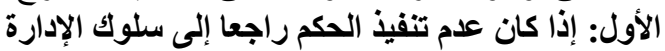

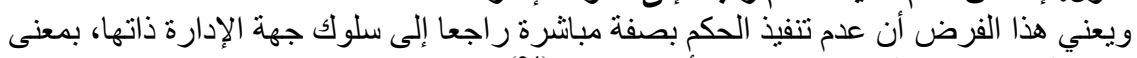

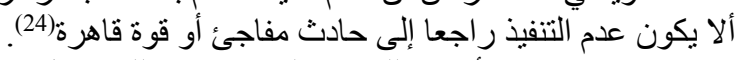

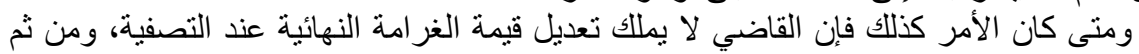

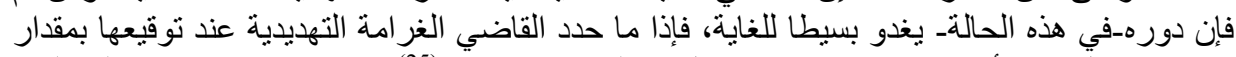

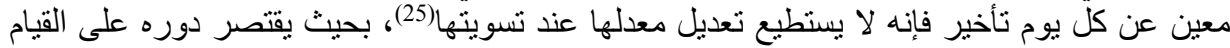
بعملية حسابية آخذا في الاعتبار مدة عدم التنفيذ وحدها. و هذا هو المبدأ الذي تستمد منه الغرامة التهديدية النهائية قوتها المؤثرة في التهايد والتخويف دون شك، و المبدأ هنا هو الثبات و التلقائية عند تصفية الغر امة التهية التهديدية النهائية(26).

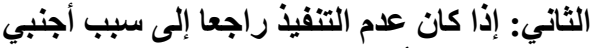

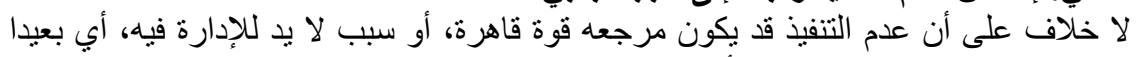

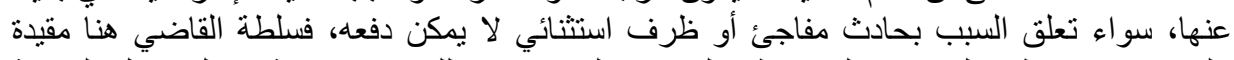

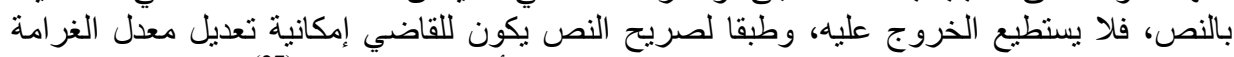

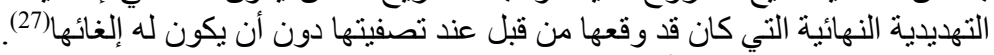

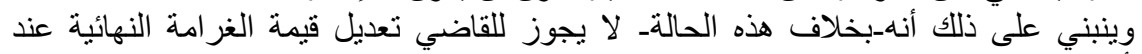

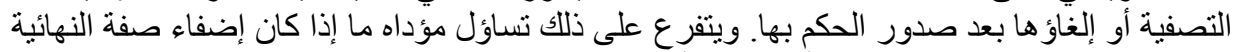

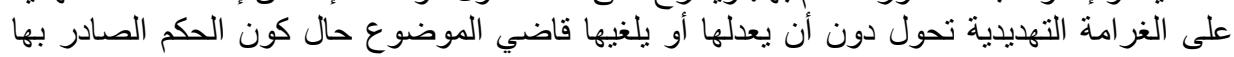

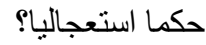

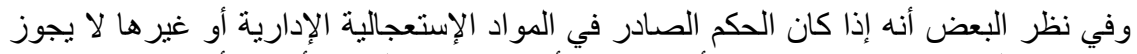

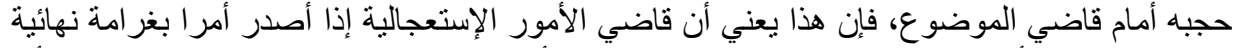

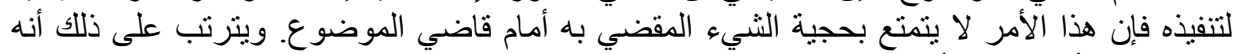

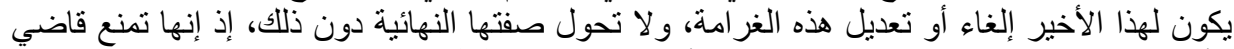

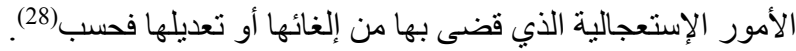


إذن إن دور القاضي يضحى بسيطا تماما في حالة تسوية الغرامة إذا كان قد حددها بمبلغ نهائي

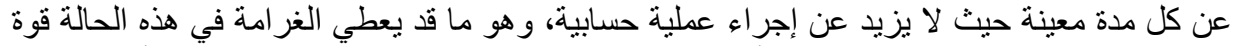
كبرى، وذلك ما لم يكن هناك قوة قاهرة أو حادث فجائي، ففي هذه الحالة فقط يجوز للقاضي أني أن يعدل في

2- في خصوص تصفية الغرامة المؤقتة:

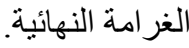

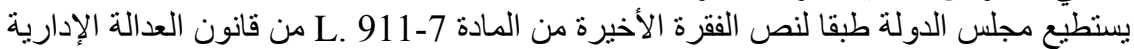

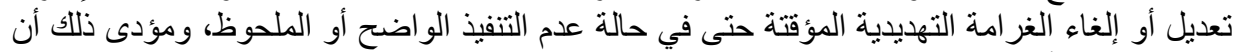

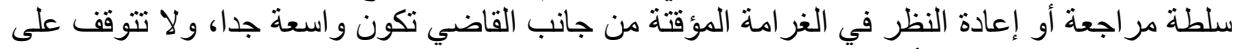

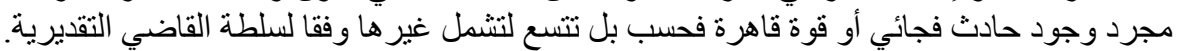

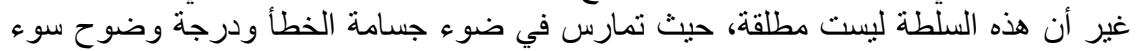

نية الإدارة(29)، و هو معيار منطقي ويتفق مع طبيعة الغر امة التهديدية.

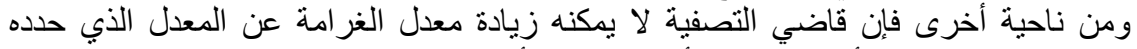

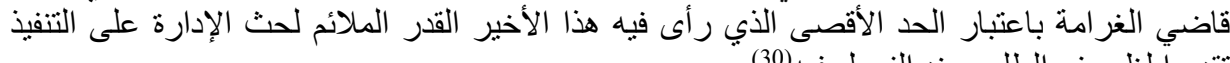

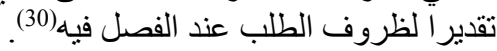

3- التصرف في مبلغ الغرامة التهديدية:

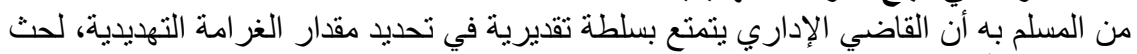

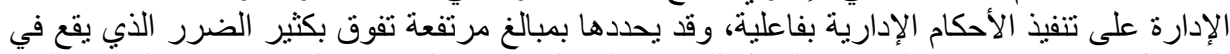

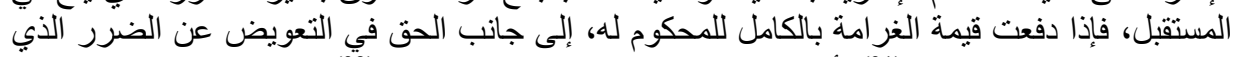

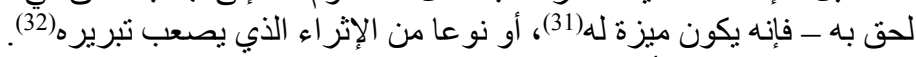

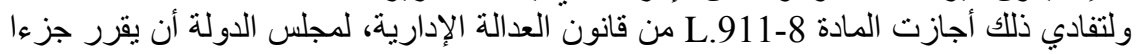

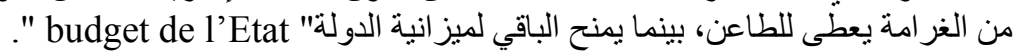

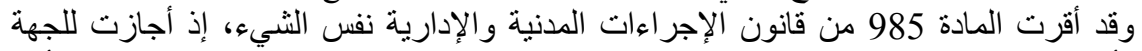

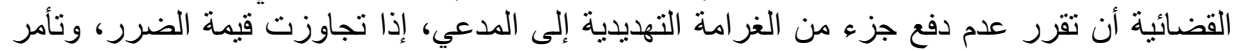

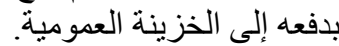

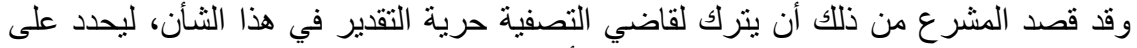

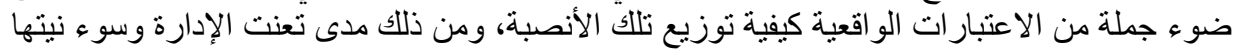
في التنفيذ، و الظروف الأناصة الخاصة بذي الثأن (33). 4- 4ـ نظام تسديد مبلغ الغرأمة التهايدية:

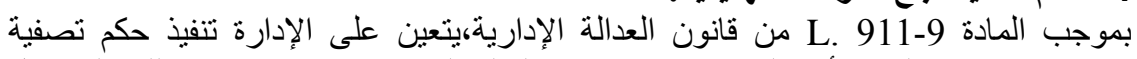

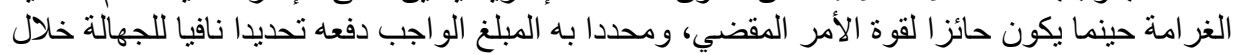

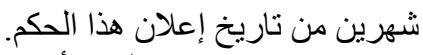

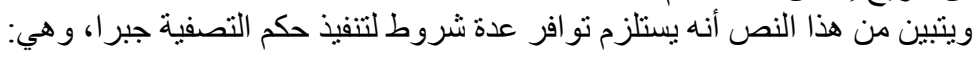

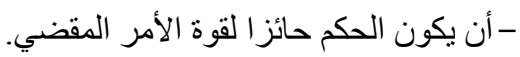

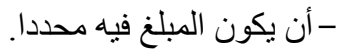

- وأن يكون صادر أن في مواجية الجهة أحد الأشخاص الاعتبارية العامة.

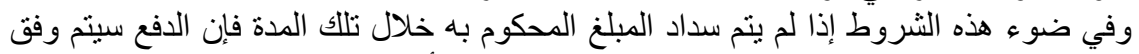

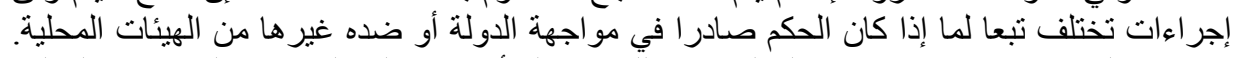

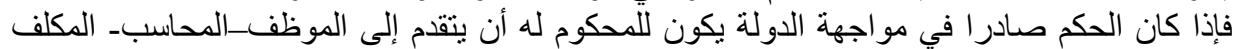

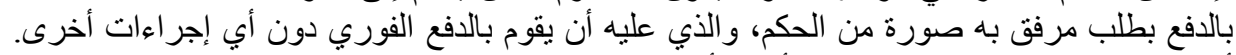

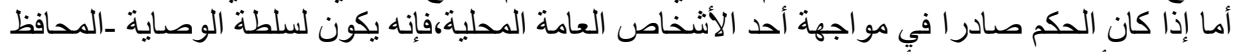
المختص- أن تقوم بإصدار أُمر الدفع. 


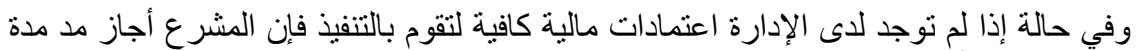

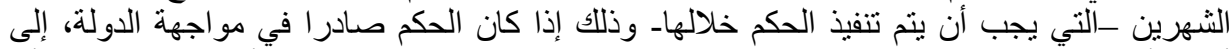

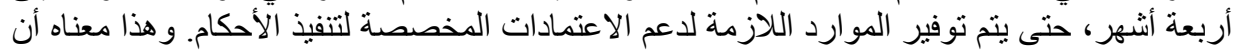

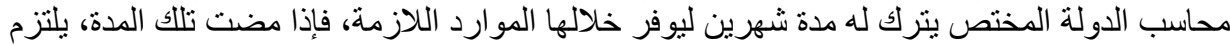

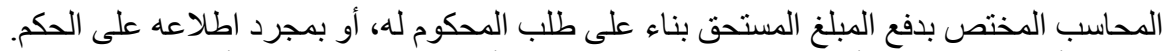

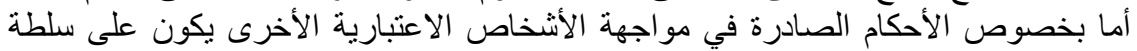

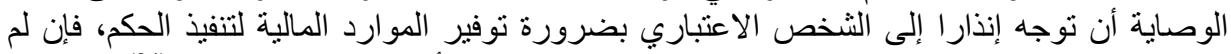

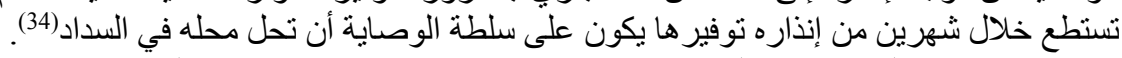

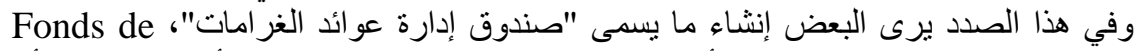

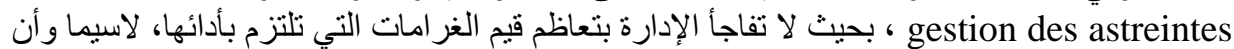

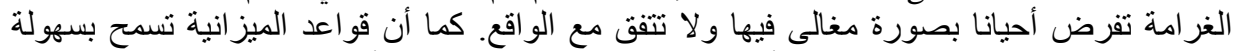

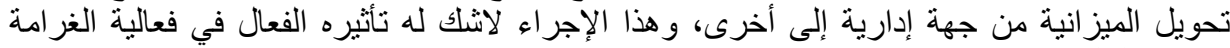

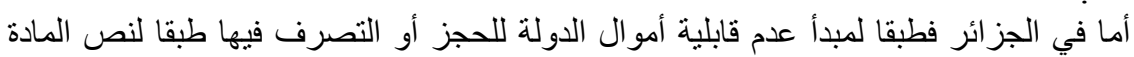
التهديدية(35)

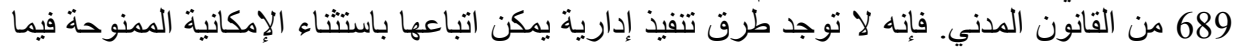

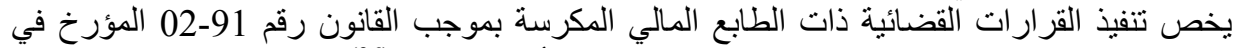

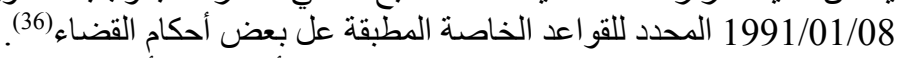

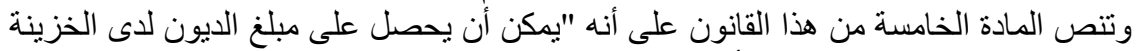

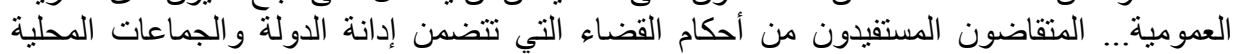
و المؤسسات العمومية ذات الطابع الإداري".

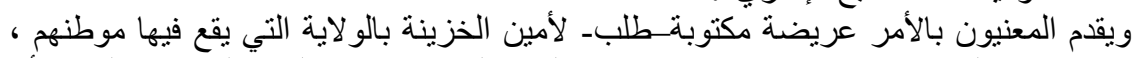

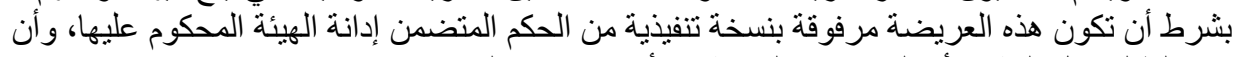

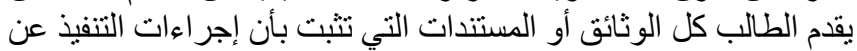

الطريق القضائي بقيت طيلة شهرين بدون نتيجة من تاريخ إيداع الملف لائ القائم بالتنفيذ (المادة السابعة).

ويتولى أمين الخزينة بالولاية بتسديد المبالغ المحكوم بها في أجل لا يتجاوز ثلاثة أشهر من إيداع طلب التحصيل على مستوى الخزينة (المادة الثامنة). 5- مسؤولية الموظف الممتنع عن التنفيذ:

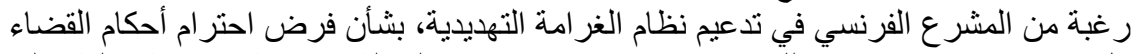

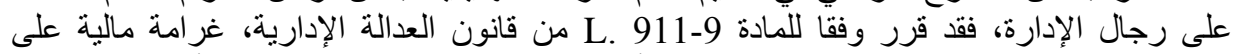

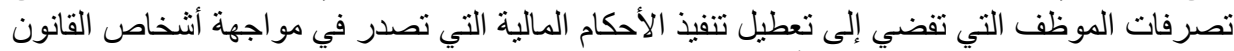

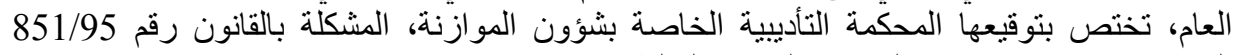

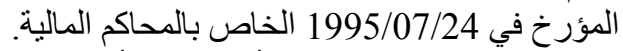

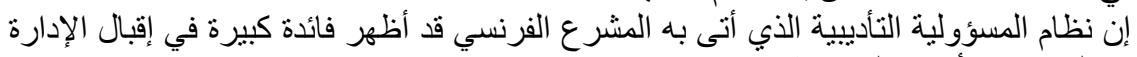
وموظفيها على تنفيذ الأحكام القضائية.

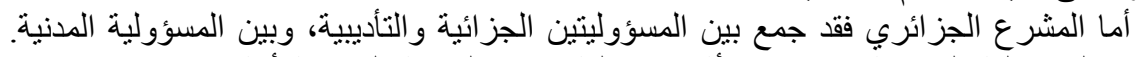

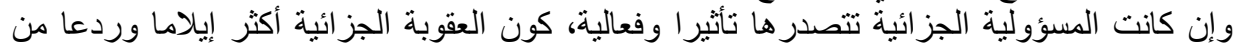

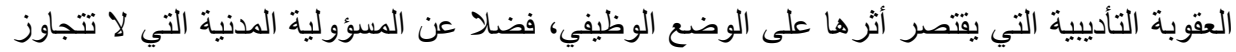

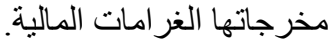

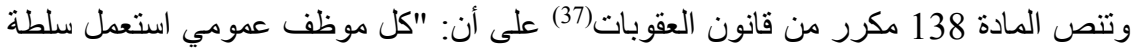

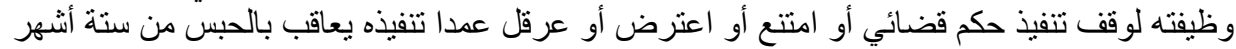

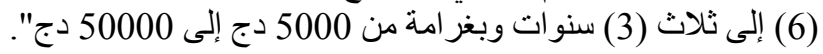




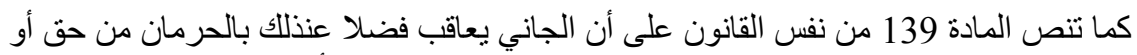

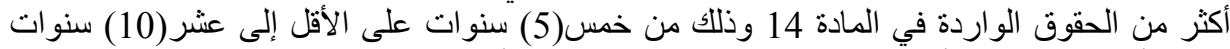

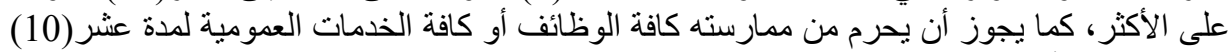
سنو ات على الأكثر (38).

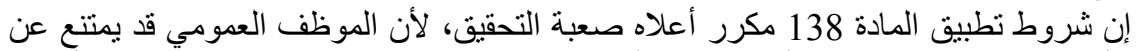

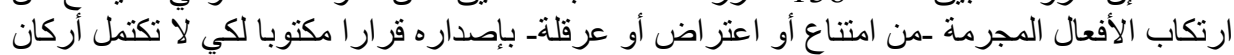

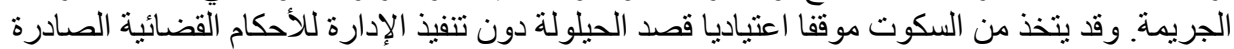

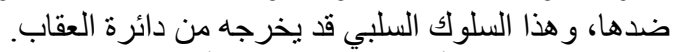

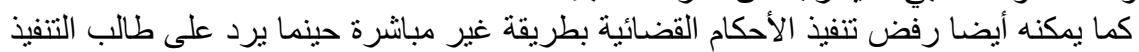

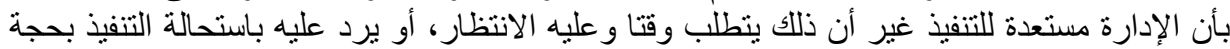
أن المطلوب منه أصبح من حقوق الغير.

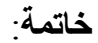

لا شكك أن آلية الغرامة التهديدية تمثل سلاحا فعالا في قبضة القاضي الإداري يمكن اللجوء إليها

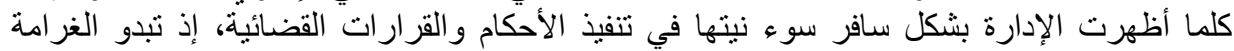

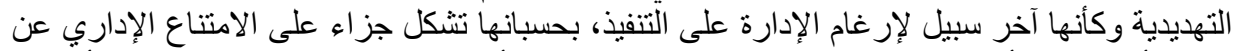

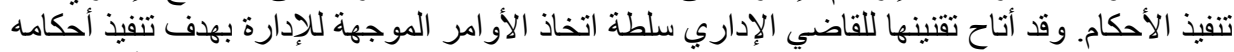

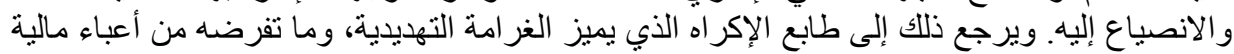

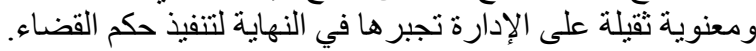

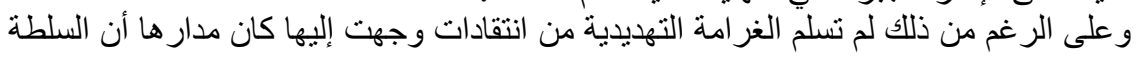

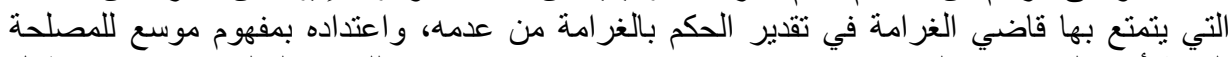

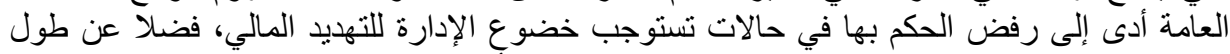

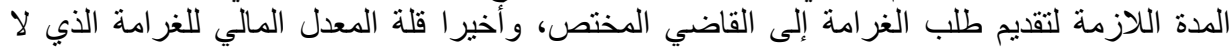

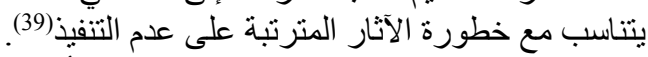

إن هذه الانتقادات بمكن تفنيدها، ذللك أن السلطة التي يتمتع بهان التها القاضي في تقدير الغرامة

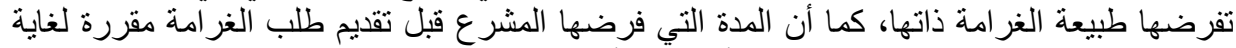

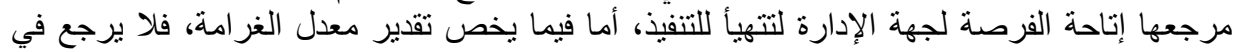

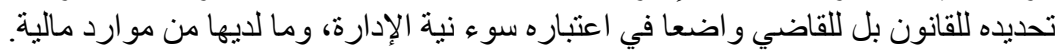

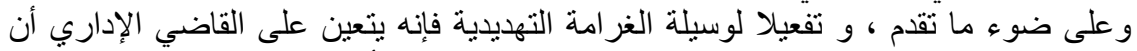

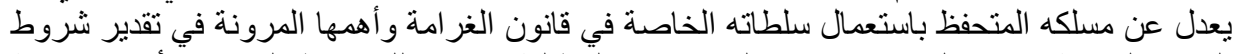

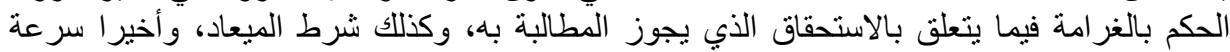

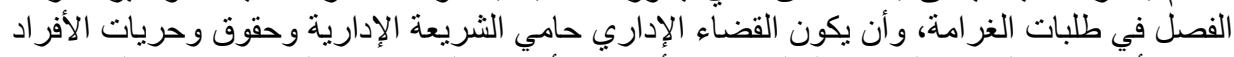

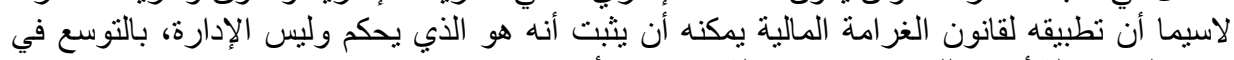
استعماله كو سيلة أخيرة للخلاص من مشكلة الغرانة عدم تنفيذ أحكامه.

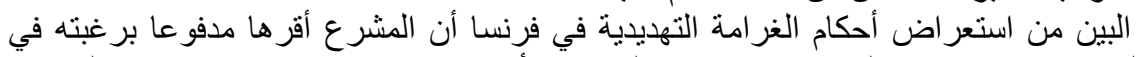

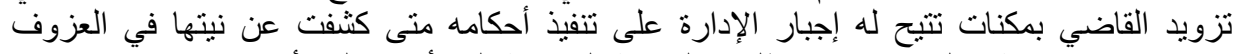

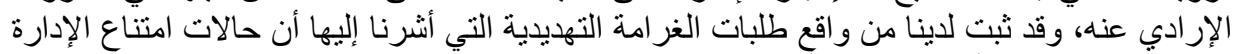

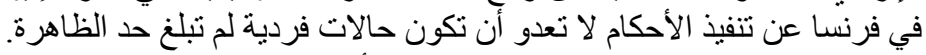

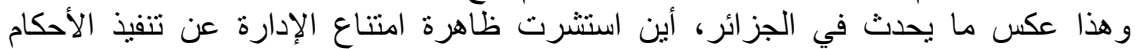

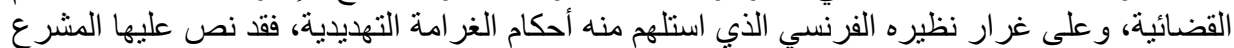

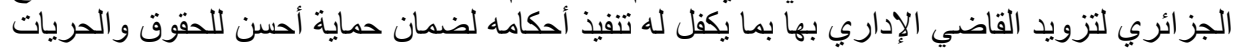

غير أن هنالك عقبة تعوق استخدام القاضي الإداري أسلوب التهديد المالي في مواجهة الإدارة،

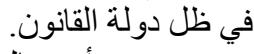




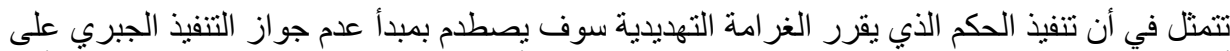

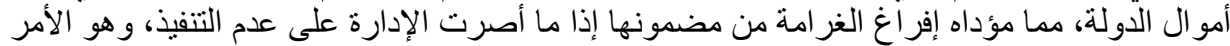

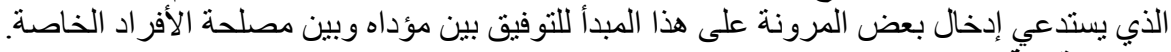

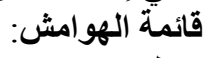

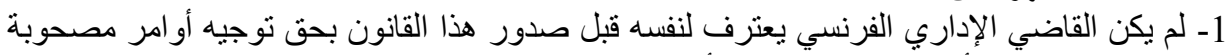

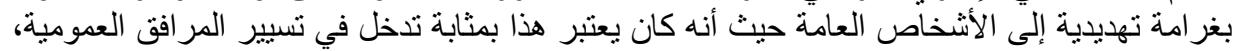

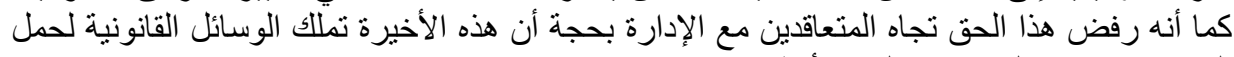
المتعاقدين معها على تنفيذ الإلتزام. أنظر : النقاه

3- أنظر: عصدت عبد الله الثيخ، الوسائل القانونية لضمانات تنفيذ الأحكام الإدارية،دار النهضة

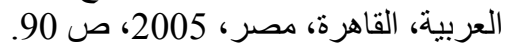
نصر الله عباس، الغرامة الإكراهية والأوامر في التنازع الإداري، منشورات مكتبة الاستقلال، بيروت،

4- J.O.R.F, 07/05/2000.

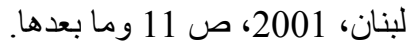

5- C.E, 28 Septembre 1995, Jehan, R.F.D.A, 1996, p 345.

6- C.E , 4 Juillet 1997, Epx Bourezak, Rec, C.E, p 278, R.F.D.A, 1997, p 815.

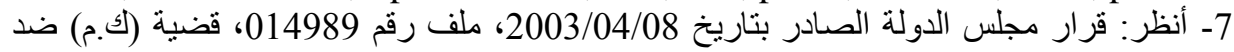

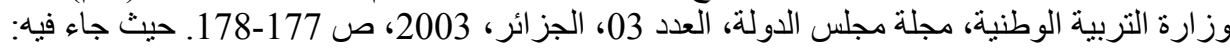

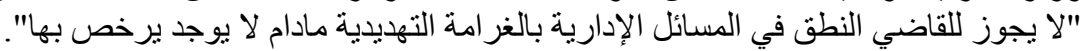

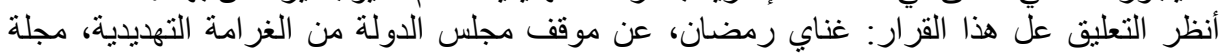

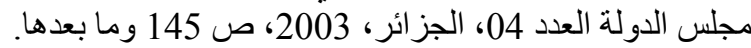
أنظر في جواز الحكم بالغر امة التهديدية من قبل القائل القاضي الإداري استنادا لأحكام المادتين 340 و 471

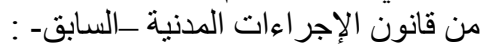

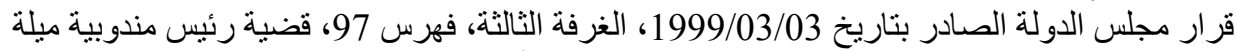

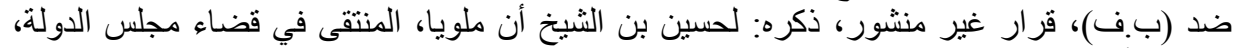

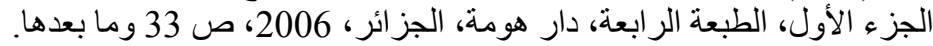

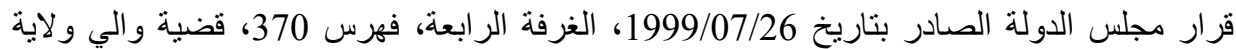

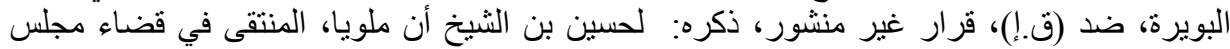

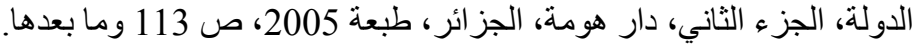

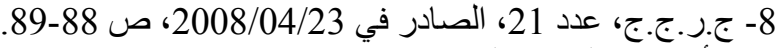
حيث أصبحت الغر امة التهايدية ممكنة في حالات منها:

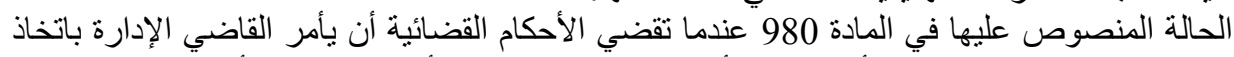
تدابير تنفيذية معينة مع تحديد أجل للتنفيذ أو عندما يقتضي تلفي التفيذ الأحكام القضائية أمر الإدارة بإصدار الإدار قرار إداري جديد في أجل محدد.

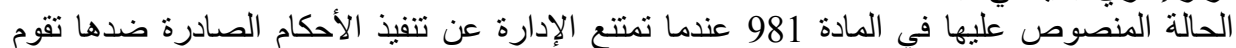
الجهة القضائية بطلب من ألمتقاضي المستفيد من الحكم القضائي بتحديد تدابير التتفيذ مع تحديد أجل اللتنفيذ والأمر بالغر امة التهديدية.

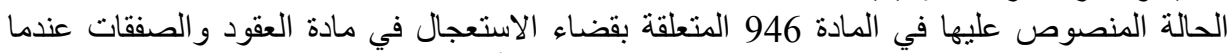

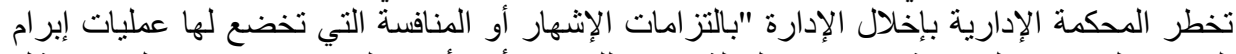
العقود والصفقات العمومية" في هذه الحالة يمكن للقاضي أن يأمر "المتسبب في الإخلال بالإمتثال 
أنظر: غناي رمضان، قراءة أولية لقانون الإجراءات المدنية والإدارية، مجلة مجلس الدولة العدد 09،

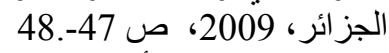

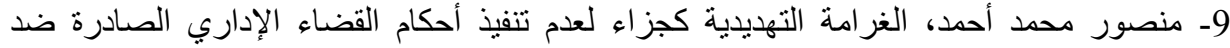

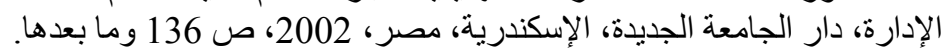

10- C.E, 8 Avril 1994, Mme Latchou Maninchetty, Rec, p 1143.

11- CHAPUS (R), Droit administratif, 12è édition, Montchrestien, Paris, 2006, p 1143.

12- DUGRIP $(\mathrm{O})$, Exécution des décisions de la juridiction administrative, répertoire de contentieux administratif, Dalloz, mise à jour 1993, T1, p 21.

13- C.E, 24 Juillet 1987, Brolin, D, 1987, p 188.

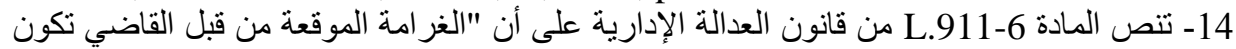
وقتية أو نهائية، ويجب العتبار ها وقتية ما لم يحدد مجلس الدولة الدادية طبيعتها النهائية".

15- CHAPUS (R), Droit du contentieux administratif, 12 è édition,

Montchrestien, Paris, 2006, p 905.

16- محمد سعيد الليثي، امتتاع الإدارة عن تنفيذ الأحكام الصادرة ضدها (الأسبابـ الأساليب- كيفية

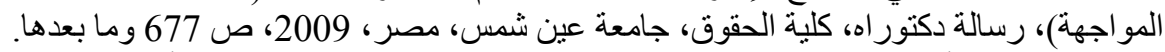
17- محمد باهي أبو يونس، الغرامة التهايدية كوسيلة لإجبار الإدارة على على تنفيذ الأحكام الإدارية، دار

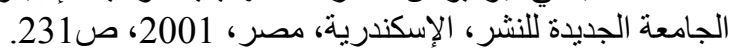

أنظر: قرار مجلس الدولة الصادر بتاريخ 1999/03/03،قرار سابق الإنشارة إليه، ص 39.

18- BON (P), Un progrès de 1'Etat de droit, la loi du 16 Juillet 1980, R.D.P, Paris, 1981, p 39.

19- C.E, 2 Juillet 1982, Rouzaud, Rec, p 264.

C.E, 6 Mai 1983, Couderc, Rec, p 187.

20- C.E, 2 Juillet 1982, Narboni, Rec, p 264.

21- C.E, 28 Mai 1986, Société « Notre-Dame Fleur», Rec, p 151.

$$
\begin{aligned}
& \text { 22- أنظر في هذا المعنى: محمد باهي أبو يونس، المرجع السابق، ص } 244 \text { وما بعد إندا. }
\end{aligned}
$$

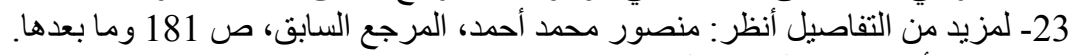

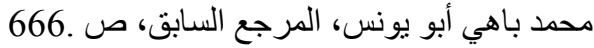

24- Mme Denis- Linton, concl, sur l'arrêt du C.E, 6 Janvier 1995, M. Daniel Boivin, M. Jean- Louis Soulat, R.D.P, 1995, p 531.

25- بسري محمد العصار، مبدأ توجيه أوامر من القاضي الإداري للإدارة وخطر حلوله محلها

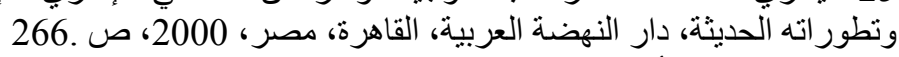

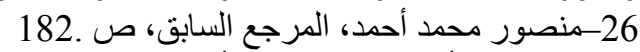

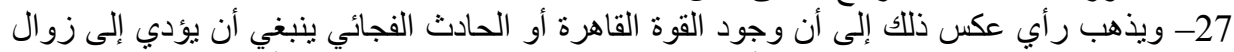

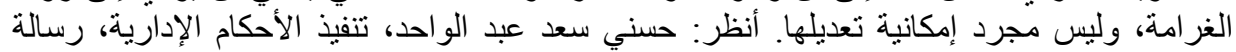

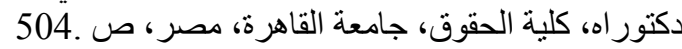

28- C.E, 24 Juillet 1987, Brolin, D, 1987, p 188.

29- BON (P), op, cit, p43.

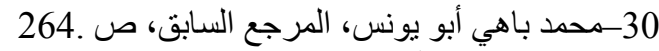

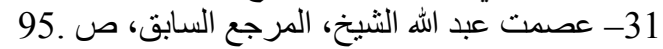

$$
\begin{aligned}
& \text { 32- حسني سعد عبد الو احد، رسالته السابقة، ص الس صل } 504 .
\end{aligned}
$$


ومن تطبيقات مجلس الدولة في القضاء بغر امة تزيد على مقدار ما طلبه المدعي: R. Sch.

C.E, 7 Octobre 1994, Lopez, Lebon, p 430 concl, R. Schwartz, R.F.D.A, 1994, p 1090, concl, R.Schwartz, note D.Pouyaud.

34- CHAPUS (R), op, cit, p 913.

33-276. محمد باهي أبو يونس، المرجع السابق، ص

35- أحمد حسن درويش، ضمانات تنفيذ أحكام قضاء مجلس الدولة "در اسة مقارنة"، رسالة دكتور اهاه،

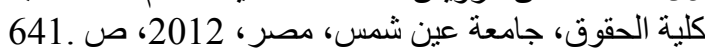

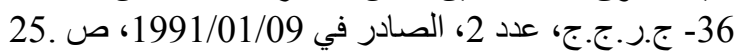

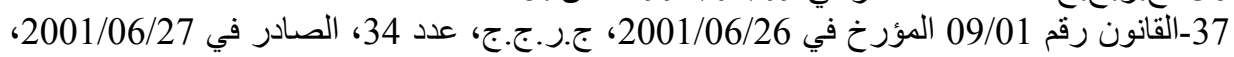

17. ص ص

38- أنظر المادتين 14 و9 مكرر من قانون العقوبات المعدل بالقانون رقم 23/06 المؤرخ في

2006/12/20

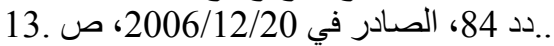

39- أنظر في انتقادات الغر امة التهايدية و التصدي لها: الها:

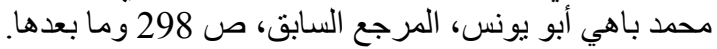

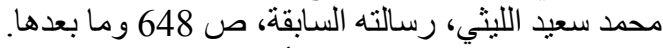

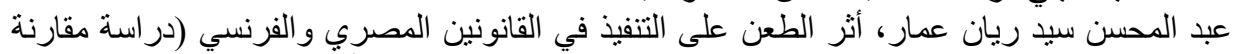

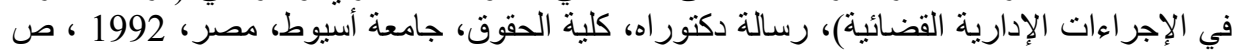

